\title{
Circuit
}

Musiques contemporaines

\section{Mon expérience privée du quatuor à cordes}

\section{José Evangelista}

Volume 11, numéro 2, 2000

Le quatuor à cordes selon Schafer

URI : https://id.erudit.org/iderudit/004665ar

DOI : https://doi.org/10.7202/004665ar

Aller au sommaire du numéro

Éditeur(s)

Les Presses de l'Université de Montréal

ISSN

1183-1693 (imprimé)

1488-9692 (numérique)

Découvrir la revue

Citer cet article

Evangelista, J. (2000). Mon expérience privée du quatuor à cordes. Circuit, 11(2), 67-68. https://doi.org/10.7202/004665ar d'utilisation que vous pouvez consulter en ligne.

https://apropos.erudit.org/fr/usagers/politique-dutilisation/ 


\title{
Mon expérience privée du quatuor à cordes
}

\author{
José Evangelista
}

J'ai pris contact avec le quatuor à travers les concerts de la Société philharmonique de Valence pendant mon adolescence. L'on y entendait beaucoup de musique de chambre et l'on y jouait des quatuors à cordes assez souvent.

Mais ma véritable découverte du quatuor est survenue lorsque j'en ai entendu un dans le salon d'une maison. Tout à coup, le son remplissait la pièce au point qu'on avait l'impression d'être devant un orchestre. En fait, le quatuor est peut-être le plus petit orchestre qui soit. II possède les quatre voix, comme le modèle vocal de la musique chorale, et il comble un maximum d'étendue sonore avec un minimum de moyens instrumentaux.

De plus, le caractère homogène de sa formation rappelle l'homogénéité du chœur. II est ainsi malléable et cet aspect est sûrement lié à sa capacité de s'adapter à des langages et des tendances différents.

On s'entend pour dire que les références obligées du quatuor sont principalement les corpus de Beethoven, Bartók et Chostakovitch. On constate que ces compositeurs ont choisi ce médium pour s'exprimer de la façon la plus intime. $C^{\prime}$ est par lui qu'ils disent leur sentiments les plus profonds, leurs angoisses, leurs déchirements, etc., plus qu'avec d'autres formations. Bien que j'admire énormément cet impressionnant corpus de musique, je demeure quand même gêné, embarrassé. Un peu comme lorsqu'une connaissance vous raconte quelque chose de très intime et qui vous met mal à l'aise.

Lorsque j'ai abordé le quatuor, j'ai essayé de m'éloigner de cette approche intimiste et dramatique des archétypes du genre. Je préfère les quatuors de Debussy et de Ravel. Chez les compositeurs actuels, j'admire beaucoup l'approche de Salvatore Sciarrino, son écriture pour cette formation devient quelque chose de léger et de brillant.

On est quand même intimidé quand on aborde le quatuor. C'est une situation semblable à celle l'écriture d'une pièce pour piano. Le répertoire est immense et, 
surtout, très prestigieux. II s'agit d'essayer d'apporter une contribution personnelle. En 1989, j'ai composé Monody Quartet, une commande du Kronos Quartet. Dans cette œuvre, j'ai tenté de briser la dimension "dialogue-de-quatre-instruments ", qu'on associe souvent au quatuor, pour aller chercher une couleur unifiée, comme s'il s'agissait d'un seul exécutant. Cependant, j'estime que c'est une œuvre plutôt ratée et je m'apprête d'ailleurs à la retirer de mon catalogue. D'ambition plus modeste est Spanish Garland, où j'ai arrangé douze mélodies traditionnelles espagnoles avec les techniques hétérophones que j'emploie depuis plusieurs années. C'est avec cette œuvre que le Quatuor Molinari a ouvert son tout premier concert, le 24 novembre 1997. 